\title{
Original Research article A Retrospective Study of Coagulation Profile in Patients of Pregnancy Induced Hypertension (PIH)
}

Dr. Shashikant Mavadiya, Dr. Ashish Jawarkar

Associate Professor, Department of Pathology, Parul institute of Medical sciences and research, Vadodara, Gujarat, India

DOI: $10.36347 /$ sjams.2020.v08i06.041

| Received: 19.06.2020 | Accepted: 26.06.2020 | Published: 30.06.2020

*Corresponding author: Dr. Ashish Jawarkar

Abstract

Original Research Article

Background: Normal pregnancy is a hypercoagulable state; a physiological safety valve aimed at preventing excessive maternal blood loss at delivery. It is essential to know the range of variations of the coagulation factors during normal pregnancy, if any specific component has to be incriminated as a causative agent for the vascular disorder. Objectives: The main objective of the study is to evaluate Coagulation Profile in Patients of Pregnancy Induced Hypertension. Methodology: This prospective study includes 120 females of uncomplicated pregnancy of age group 16-35 years as a control group and 120 females of same age group with pregnancy induced hypertension (PIH) attending obstetric outdoor patient department (OPD) of our institute from January 2005 to December 2006. Blood samples are collected from all participants for coagulation study that includes Platelet Count (PC), Prothrombin Time (PT) and Activated Partial Thromboplastin Time (APTT). Results obtained are analyzed statistically to see the significance of difference by calculating p-value. P-value less than 0.05 is considered as a difference of significance. Results: Among total 120 PIH cases, 44 were mild GH, 11 cases were severe GH, 34 cases were mild preeclampsia and 31 cases were in severe preeclampsia group. The mean value of PT and APTT is found to be high in PIH cases as compared to control group. Conclusion: The specific coagulation parameters like Platelet count, PT and, APTT can be safely used as an early indicator for the assessment of severity of PIH cases and can be used to monitor the progression of gestational hypertension to preeclampsia.

Keywords: Preeclampsia, Pregnancy, PT, APTT, Platelet count.

Copyright @ 2020: This is an open-access article distributed under the terms of the Creative Commons Attribution license which permits unrestricted use, distribution, and reproduction in any medium for non-commercial use (NonCommercial, or CC-BY-NC) provided the original author and source are credited.

\section{INRODUCTION}

Hypertension is one of the common medical complications of pregnancy and contributes significantly to maternal and perinatal morbidity and mortality. Hypertension is a sign of an underlying pathology which may be pre-existing or appear for the first time during pregnancy [1]. Various hematological changes like numerical and functional platelet abnormalities, alteration in hemoglobin and erythrocyte parameters and hypercoagulable state may be seen. Pregnancy-induced hypercoagulability is probably a physiologically adaptive mechanism to prevent post partum hemorrhage [2, 3]. Pregnancy changes the plasma levels of many clotting factors, such as fibrinogen, which can rise up to three times its normal value. Thrombin levels increase. Protein S, an anticoagulant, decreases. However, the other major anticoagulants, protein $\mathrm{C}$ and antithrombin III, remain constant [4].

In pregnancies with preeclampsia coagulation cascade is generally activated. Preeclampsia is a highly thrombotic and pro-coagulant state with platelet activation and thrombin and fibrin formation. About $20 \%$ of patients have altered coagulation.

According to the criteria of the International Society of the Study of Hypertension in pregnancy, Preeclampsia is defined as the Blood pressure $\geq 140 / 90$ $\mathrm{mm} \mathrm{Hg}$ occurring after 20 weeks of gestation with proteinuria $\geq 300 \mathrm{mg} /$ day or urinary protein/creatinine ratio $=30 \mathrm{mg} / \mathrm{mmol}$.

Hence this study was done to study the platelet and coagulation abnormalities occurring in patients of PIH including platelet count, PT and APTT parameters.

\section{Materials And Methods}

This Retrospective study was conducted in department of pathology at M.P shah medical collge, jamanagar, Gujarat, India and it includes 120 females of uncomplicated pregnancy of age group 16-35 yr as a control group and 120 females of same age group with pregnancy induced hypertension attending obstetric 
OPD of our institute from January 2005 to December 2006.

\section{Control Group}

This group comprised of pregnant women in 3rd trimester with normal blood pressure, no proteinuria or edema $(n=120)$.

\section{Study Group}

This group comprised of 120 pregnant women with blood pressure at or above $140 / 90 \mathrm{~mm}$ of $\mathrm{Hg}$ on at least two occasions, six or more hours apart in 3rd trimester of the current pregnancy together with or without proteinuria, edema, convulsions and coma.

The cases with pre-existing hypertension and associated co morbid diseases such as diabetes mellitus, auto immune disorders, other known bleeding disorders, neoplastic diseases, heart diseases and cases on anticoagulants were excluded from the study.

After obtaining consent, under aseptic precaution, venous blood was collected in Sodium citrate and EDTA vacutainer tube. All the samples were tested for coagulation profile (PT and APTT) and platelet count. Platelet count was done in 3 part automated hematology analyzer while PT and APTT were done on automated coagulation analyzer.
PIH cases were classified into following categories:-

A. Gestational hypertension

1) Mild gestational hypertension (Mild GH)

2) Severe gestational hypertension (Severe $\mathrm{GH})$

B. Preeclampsia

1) Mild preeclampsia

2) Severe preeclampsia.

Chi square test and $\mathrm{p}$ value is calculated by using Graph pad Prism software

\section{RESULTS}

A total of 240 pregnant females were included in the study, out of which 120 were controls and 120 were in study group. Distribution according to age and diagnosis as follows.

Majority of females (42.5\%) are from age group 26-30 yr followed by 21-25 yr age group (37.5\%)

Table-1: Age wise distribution of participants

\begin{tabular}{|l|l|l|}
\hline Age $(\mathbf{y r})$ & Number of cases $(\mathbf{n = 1 2 0})$ & Percentage $\%$ \\
\hline $16-20$ & 09 & $7.5 \%$ \\
\hline $21-25$ & 45 & $37.5 \%$ \\
\hline $26-30$ & 51 & $42.5 \%$ \\
\hline $31-35$ & 15 & $12.5 \%$ \\
\hline Total & 120 & 100 \\
\hline
\end{tabular}

Table-2: Showing age wise distribution of various categories of PIH cases

\begin{tabular}{|l|l|l|l|l|}
\hline Age $(\mathbf{y r})$ & Mild GH $(\mathbf{n}=\mathbf{4 4})$ & Moderate GH $(\mathbf{n}=\mathbf{1 1})$ & Mild Preeclampsia $(\mathbf{n}=\mathbf{3 4})$ & Sever Pre eclampsia $(\mathbf{n}=31)$ \\
\hline $16-20$ & $3(8.18 \%)$ & $1(10.9 \%)$ & $2(5.8 \%)$ & $5(16.12 \%)$ \\
\hline $21-25$ & $25(56.81 \%)$ & $5(45.45 \%)$ & $11(32.35 \%)$ & $10(38.70 \%)$ \\
\hline $26-30$ & $12(27.27 \%)$ & $3(37.72 \%)$ & $19(55.88 \%)$ & $15(58 \%)$ \\
\hline $31-35$ & $04(9 \%)$ & $2(21.8 \%)$ & $02(5.8 \%)$ & $03(9.67)$ \\
\hline Total & $44(100 \%)$ & $11(100 \%)$ & $34(100 \%)$ & $31(100 \%)$ \\
\hline
\end{tabular}

Mean values of platelet count, PT and APPT of control and study group and individual group are as shown in Table 2 and 3. Mean values of PT and APTT fall in normal reference range in all groups, but when compared with increasing grade of severity it shows gradual increase. Decrease in platelet count is statistically significant $(\mathrm{p}<0.05)$.

There is statistically significant increase in PT $(\mathrm{p}<0.005)$ and APTT $(\mathrm{p}<0.05)$ when compared between study and control group using unpaired T test (Table-3).

Table-3: Comparison of coagulation profile in different categories of PIH

\begin{tabular}{|l|l|l|l|l|l|}
\hline Parameter & $\begin{array}{l}\text { Control } \\
\text { Group(n=100) }\end{array}$ & $\begin{array}{l}\text { Mild } \\
\text { GH(n=44) }\end{array}$ & $\begin{array}{l}\text { Moderate } \\
\text { GH(n=11) }\end{array}$ & $\begin{array}{l}\text { Mild } \\
\text { Preeclampsia(n=34) }\end{array}$ & $\begin{array}{l}\text { Sever Pre } \\
\text { eclampsia(n=31) }\end{array}$ \\
\hline Age $(\mathrm{yr})$ & $26.09 \pm 3.4$ & $25.08 \pm 3.4$ & $25.47 \pm 2.50$ & $26.76 \pm 2.9$ & $25.6 \pm 3.82$ \\
\hline Wk of Gestation & $35.16 \pm 3.01$ & $36.26 \pm 3.01$ & $35.68 \pm 3.35$ & $36.21 \pm 3.65$ & $35.64 \pm 3.66$ \\
\hline Platlet count(lac/mm $\mathrm{mm}^{3)}$ & $3.25 \pm 1.59$ & $2.59 \pm 0.46$ & $2.35 \pm 0.54$ & $1.91 \pm 0.32$ & $1.22 \pm 0.62$ \\
\hline PT(sec) & $13.12 \pm 1.12$ & $14.12 \pm 0.98$ & $15.19 \pm 0.75$ & $16.32 \pm 3.1$ & $17.49 \pm 2.9$ \\
\hline APTT(sec) & $26.58 \pm 1.88$ & $28.12 \pm 1.34$ & $29.12 \pm 1.24$ & $32.56 \pm 4.5$ & $36.14 \pm 7.41$ \\
\hline
\end{tabular}

Table-4: Comparison of platelet count, PT and APTT of control with each group

\begin{tabular}{|l|l|l|l|l|}
\hline No & Group & $\begin{array}{l}\text { Platlet count } \\
\text { p-value }\end{array}$ & $\begin{array}{l}\text { PT } \\
\text { P-value }\end{array}$ & $\begin{array}{l}\text { APTT } \\
\text { P-value }\end{array}$ \\
\hline 1 & Control Vs Mild GH & $>0.05$ & $<0.05$ & $<0.05$ \\
\hline 2 & Control Vs Moderate GH & $<0.05$ & $<0.05$ & $<0.05$ \\
\hline 3 & Control Vs Mild Preeclampsia & $<0.05$ & $<0.05$ & $<0.05$ \\
\hline 4 & Control Vs Mild Preeclampsia & $<0.05$ & $<0.05$ & $<0.05$ \\
\hline
\end{tabular}


When coagulation parameters were compared between control group and each study group significant difference between all parameters was seen except the platelet count which showed no significant decrease in gestational hypertension as compared with control (Table-4).

\section{DisCUSSION}

Preeclampsia is an idiopathic multisystem disorder specific to human pregnancy and the puerperium [5]. Hematological abnormalities such as thrombocytopenia and decrease in some plasma clotting factors may develop in preeclamptic women [6]. Subtle changes suggesting disseminated intravascular coagulation (DIC) is one of the serious outcome of preeclampsia. Thus, coagulation testing is to be done in these patients to rule out DIC and HELLP (hemolysis, enzyme elevation and low platelet) syndrome. From the historical point of view, earlier it was stated that only serial measurements of platelet count was adequate for intrapartum screening. Later, combination of platelet count and APTT, platelet count and liver function tests platelet count and lactate dehydrogenase, platelet count and antithrombin [7] were suggested for early detection and screening of the patients with preeclampsia.

The findings of the present study and many other studies such as Leduc et al., [8] (65\%) and Naaz A et al., [9] (60\%), also confirm that PIH is more prevalent in primigravida. Maximum numbers of cases were between 18 to 29 years of age which is comparable with the studies of Shivkumar S [10], Prakash J [11], Priyadarshini G [12], Nirmala T [13] and Lakshmi VC [14].

Younger age of occurrence of PIH in these studies testify the early age of marriage and first pregnancy in this country compared to western countries. There was fall in mean platelet count with increasing severity of PIH in present study. Reduction in platelet count can be attributed to platelet activation, platelet aggregation and platelet consumption which can be present during and even before the onset of disease. Platelet activation may lead to increase degeneration of thromboxane A2 and serotonin release, in turn increase vasoconstriction and platelet aggregation [15].

\section{Conclusion}

The coagulation parameters, especially Platelet count, PT and, APTT can be safely used as an early indicator for the assessment of severity of PIH cases and can be used to monitor the progression of gestational hypertension to preeclampsia.

\section{REFRENCES}

1. Onisai M, Vladareaner AM, Bumbea H, Clorascu M, Pop C, Andrei C. A study of haematological picture and of platelet function in preeclampsiareport of a series of cases. J of Clin Med. 2009;4: 326-7.

2. Naaz A, Padugupati S, Sarma, Sushma P. A Study on Coagulation Profile in Pregnancy Induced Hypertension Cases. IOSR Journal of Biotechnology and Biochemistry. Sep. - Oct. 2015;1(6): 82-88.

3. Nirmala T, Kumar Pradeep. Study of Coagulation profile in PIH. Indian Journal of Pathology and Oncology. 2015; 2(1):1-6.

4. Metz J, Cincotta R, Francis M, DeRosa L, Balloch A. Screening for consumptive coagulopathy in preeclampsia.Int J GynaecolObstet, 1994 Jul; 46(1):3-9.

5. Steegers EA, von Dadelszen P, Duvekot JJ, Pijnenborg R. Preeclampsia. Lancet. 2010;376(9741):631-644

6. Roberts JM, Redman CW. Pre-eclampsia: more than pregnancy-induced hypertension. Lancet, 1993; 341: 1447-51.

7. Valensise H, Vasapollo B, Gagliardi G, Novelli GP. Early and late preeclampsia: two different maternal hemodynamic states in the latent phase of the disease. Hypertension. 2008; 52(5):873-880.

8. Leduc L, Wheeler JM, Kirshon B, Mitchell P, Cottan DB. Coagulation profile in severe preeclampsia. Obstet Gynecol, 1992 Jan; 79(1):148.

9. Naaz A, Padugupati S, Sarma, Sushma P. A Study on Coagulation Profile in Pregnancy Induced Hypertension Cases. IOSR Journal of Biotechnology and Biochemistry. Sep. - Oct. 2015;1(6): 82-88.

10. Sharma SK, Philip J, Whitten CW, Padakandla UB, Landers DF. Assessment of changes in coagulation in parturients using thromboelastography. American society of Anaesthesiologistinc, 1999; 90:385-390

11. Prakash J, Pandey LK, Singh AK, Kar B. Hypertension in pregnancy: Hospital based study. J Assoc Physicians India. 2006; 54:273.

12. Priyadarshini G, Mohanty RR. Assessment of Coagulation Profile and its Correlation with Severity of Preeclampsia in Women of Odisha. International Journal of Physiology. 2014; 3(1):135-140.

13. Nirmala T, Kumar P. Study of coagulation profile in PIH. Indian Journal of Pathology and Oncology. 2015; 2(1):1-6.

14. Lakshmi CV. Comparative Study of Coagulation Profile in Mild Pre-eclampsia, Severe Preeclampsia, and Eclampsia. Int $\mathbf{J}$ Sci Stud. 2016;4(4):180-183

15. Gallery ED. Modern management of hypertension in pregnancy. Aust N Z J Med. 1980;10: 246-52. 